\title{
Innovation potential as a guarantee of effective industrial enterprises development in the digital economy
}

\author{
Vera Ansarovna Vasyaycheva $^{1, *}$, Galina Aleksandrovna Sakhabieva ${ }^{1}$, Olga Vladimirovna Novoselova ${ }^{1}$,and Elena Petrovna \\ Solodova ${ }^{2}$
}

${ }^{1}$ Samara National Research University Samara, Russian Federation

${ }^{2}$ Moscow city pedagogical university Samara branch, Samara, Russian Federation

\begin{abstract}
The purpose of this article is to analyze and identify the key problems and reserves of growth of innovative activity of Russian industrial enterprises from the standpoint of the principles of development of the new economy. The works of domestic and foreign authors were studied to achieve this purpose. The study included methods of system analysis, methods of expert survey, method of statistical data analysis, which together allowed identifying the essence of the problem under study. The results of research were aimed at identifying the role of digital innovation, i.e. the introduction and use of new information and communication technologies to improve and manage business processes, increase the competitiveness of the domestic economy.
\end{abstract}

\section{Introduction}

Innovative activity is of great importance in the formation of competitive advantages and ensuring stable economic development of Russian industrial enterprises in the context of the transition to a new economy and the digital restructuring of production.

The increase in innovation activity depends on the coherence of the mechanism of interaction of methods and factors that contribute to the efficiency of innovation, starting from the R\&D stage and ending with the introduction of science-intensive technologies and the mass production of unique products. The growth of innovative and digital potential is provided, first of all, through the rational use of own resources, internal reserves and capabilities of enterprises [1].

The aim of the study is to identify the conditions and analyze the features of the process of digitalization of domestic enterprises.

The main task is to develop a set of measures to improve the quality and efficiency of their innovation activities for the development of innovative, digital and competitive potentials.

Scientific novelty: due to the formulation of the problem and the definition of the most significant difficulties in the process of digital transformation of the domestic economy.

\section{Innovation potential as a guarantee of effective industrial enterprises development in the digital economy}

The above problems at different periods of time were explored in the studies of both international (Porter M.E., Scott B.S., Marshall A., Drucker F., Clark J.B., Solow R.M., Freeman K., Hayek F.A.,. Harrod R.F., Schumpeter J.A. etc.) and domestic researchers: Belotserkovsky O.M., Glazyev S. Y., Gershman M.A., Kondratieff N.D., Kuznetsov B.L.,. Lavrikova Yu.G, Romanova O.A., Sukharev O.S., Tatarkina A.I., etc. Conceptual aspects of innovative transformation of Russian industrial enterprises are presented in the studies of Baldin K.V., Voropaev V.I., Ivanov G.I., Ilyenkova S.D., Kolokolov V.A., Kuznetsov B. L., Medynsky V.G., Razu M. L. Raizberg B.A., Fatkhutdinov R.A., etc.

It should be noted that many authors consider that innovation and technological development is caused by the introduction of high technologies corresponding to the technological order, the creation of developed infrastructure; openness and interaction of the national economy with the global economy; support for free zones, zones with advanced development; the establishment of benefits for innovation of small and medium-sized businesses, high-tech industries; orientation of producers to consumer interests and stimulation of continuous creation of innovations at the expense of reforms at the legislative level; improvement of the legislation defining the rights to intellectual activity [2].

\footnotetext{
* Corresponding author: v.vera123@yandex.ru
} 
Despite the large number of scientific publications on the issues under consideration, some of them remain unresolved. In this regard, it seems relevant to develop theoretical and practical recommendations in this field of research to ensure the effective development of domestic industry [3].

In particular, the modern system of economic relations, based on innovative growth, closely associated with the formation of digital potential and institutional aspects of the digital economy, is poorly sanctified in the works of domestic economists.

\section{Material and methods}

The conducted study is based on the statistical analysis of communicative factors that allow to assess the impact of innovative activity on the digital transformation of the economy of Russian industrial enterprises; economic conditions for the implementation of innovative activity and a system of indicators characterizing the readiness for the development of digital potential: digital competitiveness, readiness for the future, scientific and technical concentration, the quality of state innovation policy, etc.

The indicators used meet Russian and international statistical standards.

It is held on the basis of:

- annual research of official statistical information carried out by the Federal;

-state statistics service: Regions of Russia. Socioeconomic indicators (2005-2017);

- information and analytical materials of various aspects reflected in the IMD WORLD COMPETITIVENESS CENTER, Digital Competitiveness Ranking (20132018);

- The program "Digital economy of the Russian Federation", approved July 28, 2017 № 1632.

\section{Results}

The results of the study showed that there are problems in creating the necessary and sufficient conditions of institutional and infrastructural nature in the processes of digitalization of the domestic economy.

The elimination of existing obstacles and limitations to the development of high-tech business processes and the prevention of the emergence of new obstacles is based on the improvement of organizational and management decisions and the implementation of measures developed in the work.

Statistical analysis of the activities of Russian manufacturing companies shows that currently they are inferior to foreign competitors in many economic, organizational and managerial indicators, which significantly complicates their entry into the global market.

Rating of Russia among the 63 countries with the most developed economies in the period 2013-2018on key indicators: competitiveness, digital competitiveness, knowledge, technology, readiness for the future and the overall rating (on a set of factors: talent, training and education, scientific concentration, regulatory framework, capital, technological base, adaptive quality, business flexibility, it integration) accordingly to statistics IMD (Institute of Management Development) World Competitiveness Center (Switzerland) has a consistently low level [4].

Analysis of the dynamics of innovation activity of Russian industrial enterprises shows that $11 \%$ of the studied enterprises were engaged in innovative activity in 2015. The share of enterprises engaged in technological innovation was $10 \%$, marketing - $2 \%$, organizational $-3 \%$. The level of innovation activity of industrial enterprises was about 10\% [5], [6].

The main source of financing of innovative activity in Russia is own funds of the companies, $54 \%$ of all expenses on technological innovations were financed at the expense of own funds of the organizations in 2015.

Funds of the Federal budget, budgets of subjects of the Russian Federation and local budgets amounted to $28 \%$ in the total amount of expenses for technological innovations in 2015. Funds of extra-budgetary funds allocated to innovation activities amounted to $2 \%$ of all costs. Foreign investment accounted for an even smaller share $(1 \%)$.

The level of innovative activity of enterprises amounted to $9 \%$ in 2016 , a decrease of $1 \%$ compared to the previous year. Such conclusions were reached at the Institute of statistical studies and Economics of knowledge at the Higher school of Economics.

The researchers explain low rates in 2016 by the decrease in the intensity of innovative processes in medium-tech industries (production of electric machines and electrical equipment, metallurgy).

However, in the context of the relative growth of innovation activity, the emergence of new models of business processes and network structures is focused mainly on traditional technical and technological solutions (Fig.1, Fig.2).

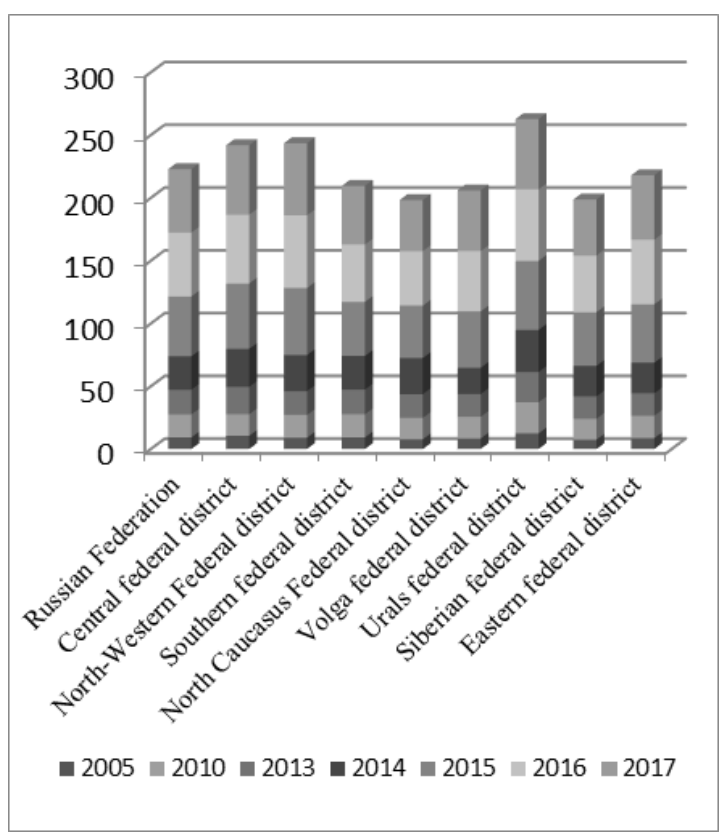

Fig. 1. Dynamics of the number of organizations using servers in the subjects of the Russian Federation. 


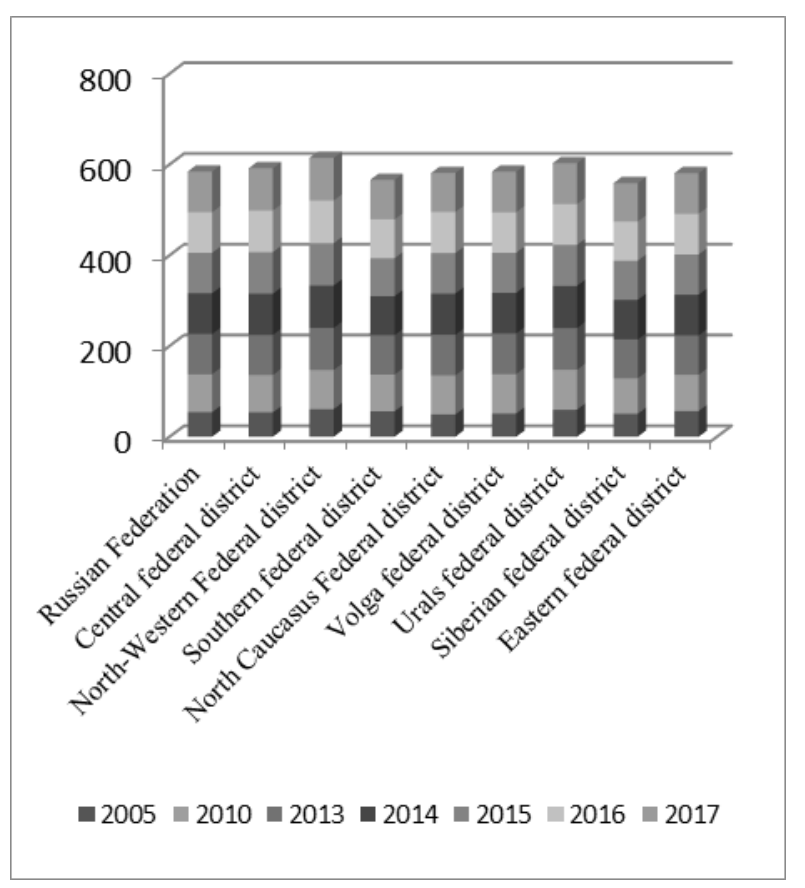

Fig. 2. Dynamics of the number of organizations using global information networks in the subjects of the Russian Federation.

The institutional aspects of the digital economy, the problems of digital potential development and the problems of business processes development in the conditions of the digital economy formation remain out of the sight of the management structures of enterprises, despite the tasks defined in the target government program "Digital economy of the Russian Federation", dated July 28, 2017.

Changes in the dynamics of the number of technological leaders of the Russian Federation, planned by the road map "Digital economy of the Russian Federation" in the period 2018-2024 are shown in Figure.3, Figure.4.

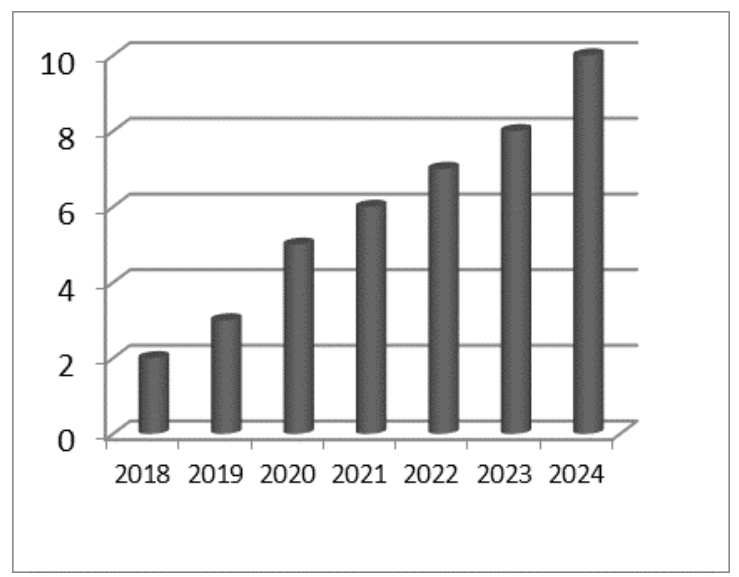

Fig. 3. Dynamics of technology leaders competitive in global markets according to the Road map of CPP-17, \%.

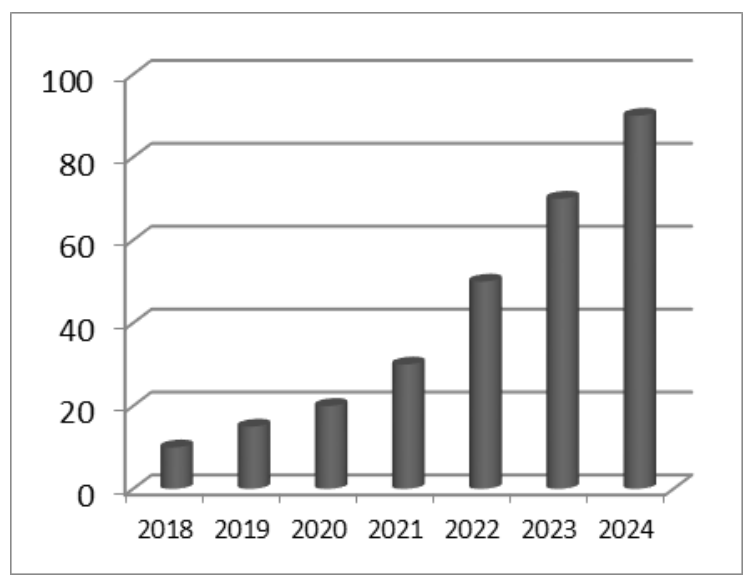

Fig. 4. The proportion of subjects secure interactions in cyberphysical systems roadmap PDC-17, \%.

Digital transformation of industry involves the consolidation of business processes of enterprises and new computer technologies in order to enhance innovation and competitiveness through the creation of reference information and innovation platforms and new business models.

Digitalization of industrial enterprises affects the main areas of their business activity: supply and sales activities (modeling of relationships with suppliers of resources and consumers of products); production activities (modeling of operational processes, including the processes of relationship between the enterprise and the employee); innovation (engineering of innovations that meet the needs of the market).

There are four levels of digital transformation of industrial enterprises according to the economist Roland Berger:

- digitalization of data;

- creation of effective communication connections;

- automation of data collection and processing;

- organization of access to consumer databases of relevant information.[7]

Progressive digitalization affects the toughening of competition between enterprises using traditional business models and implementing modern technologies and relationships with suppliers and consumers through Omni-channels.

The readiness of Russian enterprises for digitalization and digital competitiveness is characterized, in particular, by the possibility of using global digital developments and technologies in the internal operations of companies. Analysis the dynamics of the application of information and communication technologies allows to note a significant increase in indicators for the period 2005-2017.

\section{Discussion}

The study revealed some dynamics of positive results in the development of emerging competencies focused on the development of markets and sectors of the digital economy, as well as the environment that creates conditions for the development of platforms and technologies, including regulatory, information 
infrastructure, human resources and information security.

It is planned to expand the implementation of measures to develop the institutional aspects of the digital economy, services to support the patenting of the results of intellectual activity on the basis of development institutions, to create a system of management of rights to the results of intellectual activity in organizations with state participation, to improve the efficiency of public services for the registration of the results of intellectual activity, creation of a network of technology and innovation support centers in cooperation with the world intellectual property organization for the period 2018 -2020.

At the present stage in the innovative activity of industrial enterprises priority is technological innovation, but the relative size of investments in technological innovation, for example, is higher in Europe than in the Russian Federation. Moreover, the scale of financial investments of European countries aimed at the development of technological and non-technological (marketing and organizational) innovations show a tendency to increase, while most of them fall on technological innovations and digitalization of the economy[8].

According to the GII (Global Innovation Index), Russia maintains a stable position in innovation development among 35 leading European countries and among 50 high-income countries. Countries participating in the ranking, together produce $98 \%$ of world GDP, on their territory which is home to $92 \%$ of the world's population.

Russia belongs to the group of countries with a high level of GDP per capita, ranking among them 39th out of 50, and among European countries-29th. According to the results of the GII, Russia is included in the fifty most innovative countries in the world. Surrounded by countries such as Canada, Australia, Norway, Switzerland, it took the fourteenth place.

Countries in this ranking occupy positions on the basis of the average for the following categories: industrial production, research and development, hightech companies, higher education, research workers, patents. However, the development of innovative activity in Russia does not meet the criteria related to the formation of an innovative economy. Target indicators of implementation of the "Strategy of innovative development of the Russian Federation for the period up to 2020" show that the share of industrial enterprises engaged in technological innovation has decreased over the past 3 years.

The overall condition of industrial development in Russia can be characterized by low competitiveness and relatively low development rates. According to the level of competitiveness and the degree of innovation activity of foreign enterprises have a higher position in comparison with the Russian.

The criteria for achieving the activation goals are considered to be the increase in the part of innovative and active industrial enterprises and the increase in the science intensity of GDP [9], [10].
Innovation in the national economy of the Russian Federation is most of all the large, economically wealthy organizations with sufficient financial, human and intellectual resources. The introduction of innovations in the field of information and communication technologies in large businesses will directly affect most of the Russian economy, as the share of large companies in Russia is $79 \%$ against $42 \%$ on average in comparable countries.

Established business is able to carry out venture capital investments and thus provide high inventive activity, as well as to influence the demand in the field of digital innovation. [11]

\section{Summary}

The market of the Russian Federation is one of the most promising sites in the world in terms of economic growth. However, today, having impressive development prospects, Russia lags behind the leaders of the world economy due to the lack of efficiency of the economic system in the field of innovation implementation and management.

The problem solution of getting out of this situation depends on the implementation of legislative reforms and organizational and managerial reforms that stimulate the activity of enterprises in this direction. Increasing innovation activity is a complex, multi-component and strategically important task, especially relevant in the current economic conditions of Russia. The effectiveness of its solution determines the state and prospects of economic development, characterizes the importance of the state in the world market, ensures the stability of the economic situation as a whole [12].

It is obvious that the growth of innovative activity of industrial enterprises, especially in terms of digital innovation, i.e. the introduction and use of new information and communication technologies to improve and manage business processes, will certainly lead to the rise of the domestic economy.

Digitalization of the economy as a modern type of management, from our point of view, requires the creation of the necessary favorable conditions:

- Availability of infrastructure for digital innovation (mobile Internet, information processing automation);

- The presence of organizational and management structures aimed at optimizing the solution of the problem in the shortest possible time;

- Training of personnel at all levels of the production hierarchy, starting with Top managers and IT specialists; - Readiness of the platform for the formation of the digital economy, including algorithmization and structuring of business processes;

- High level of use of global digital trends and developments in internal operations of companies (IoC, IoD, IoS, IoT, IIoT, IoE, IoTSP, IoRT, IoET and P2P, $\mathrm{M} 2 \mathrm{M}, \mathrm{P} 2 \mathrm{M}$, etc.).

The implementation of the innovative scenario of economic development is impossible without the support of the state in the framework of a comprehensive policy to support and stimulate innovation, involving the 
creation of a national innovation system. According to the authors of the GII, Russia has great potential in such an innovative component as education. It is obvious that education has a significant impact on all other areas of activity, which are also designed to provide innovative development of the national economy [13]. Russia is second only to South Korea in this indicator. However, it should be noted that without broad and operational support from the state, it is impossible to avoid a decline in education and ensure its sustainable development [14].

\section{Conclusion}

1.The study showed that the creation of innovations should be the norm of doing business, i.e. industrial enterprises should realize the possibility of constant updating. At each stage of the innovation process, appropriate management mechanisms should be used, taking into account all the features of this stage. Only such an approach can ensure successful and effective management of innovations.

2. Innovative activity of any enterprise is the result of the implementation of a set of management actions that in the variable States of the external and internal environment revitalize innovation, increase its intensity and allow receiving and using competitive advantages. Since only a small proportion of innovations in their total number allows obtaining an innovative product and reaches the stage of commercialization, innovative activity contributes to an increase in the total number of innovations and increases the probability of acquire results from the implementation of innovative activities.

3.The authors definethe key priorities of scientific and technological development of the country in the context of digitalization of the economy to ensure technological breakthroughs and expanding the share on the emerging markets, increasing the share of new high tech and knowledge-intensive industries in the gross domestic product through the innovative transformation of industrial enterprises.

4. The main objective of the innovation management system of an industrial enterprise is to ensure the competitiveness of the enterprise at each stage of the innovation process for creation of high-tech products, commercialization, increasing of profitability and payback of scientific research.

In order to ensure the achievement of this goal, it is necessary to solve the following tasks:

- Analysis of priority areas of research and development;

- Study and formation of methodology and methods of selection of innovative developments;

- Development of organizational and management structures aimed at optimizing the solution of the problem;

- Creation of the system of personnel support of innovative activity;

- Development of a mechanism for financing innovation;

- Development of methods to stimulate innovation;

- Creation of infrastructure for digital innovation;
- Creation of a platform for the formation of the digital economy, including algorithmization and structuring of business processes;

- Usage of global digital trends and developments in the internal activities of companies;

- Provision of professional staff at all levels of the production hierarchy;

- Formation of innovation infrastructure.

Taking into account the identified conditions for increasing the innovative activity of enterprises and the factors that prevent the intensive introduction of innovations, it is necessary to take into account the following in the algorithm of forming an effective innovation system:

- Innovation management should "smoothly" enter into the enterprise management system taking into account the intensive changes in the external environment;

- The legislative framework for innovation should encourage innovation through tax and customs benefits, sparing credit lines, and reducing technological barriers; - The distribution of risks for innovation should be a compromise, which necessitates the development of the insurance market and the support of the government.

\section{References}

[1] Vasyaycheva, V. A. Improving the competitiveness of transport engineering enterprises on the basis of innovative project management: monograph. // Samara: Samara national research University named after academician S. Korolev. 2017. 177

[2] Mishchenko, L.Ya.,Arutyunov, E.Yu. Formation of the mechanism ofindustrial Corporation development management: monograph. //Krasnodar, 2002.128

[3] Vasyaycheva, V. A. Theoretical and methodological issues of industrial enterprises competitiveness management: monograph. //Samara: publishing House " Samara University»/ 2016. 160

[4] IMD WORLD DIGITAL COMPETITIVENESS RANKING. $2018 \mathrm{https} / /$ www.imd.org/wcc/worldcompetitiveness-center-rankings/world-digitalcompetitiveness-rankings-2018/

[5] Association of innovative regions of Russia [Electronic resource]: http://i-regions.org

[6] Federal state statistics service. http://www.gks.ru/wps/wcm/connect/rosstat main/ro sstat/ru/statistics/science_and_innovations/science/\#/.

[7] Roland 2015 Berger.The digital transformation of industry, BDI. //Study The Digital Transformation of Industry.pdf. $2015.217-20$, https://english.bdi.eu/media/topics/europe/publicatio ns/201503

[8] Sakhabieva 2017 G A Management of investment activity of the enterprise // Management accounting. 2017. No. 2. 98-106

[9] Kuzyk B N , Kushlin V I, Yakovets and Yu V Forecasting 2011 strategic planning and national programming.// M.: Economics, 2011. 604 
[10] Sheko 1999 Innovative economic mechanism. //Problems of management theory and practice. 1999. No.2. 71-78

[11] Sakhabieva G A 2017 Analysis of the principles of formation of sustainable development of domestic enterprises //Problems of effective use of the scientific potential of society: collection of articles of the International scientific-practical conference. Ufa, 2017. 102-05

[12] Sakhabieva G A and Vasyaycheva VA 2015 Analysis of the transport engineering industry of the Russian Federation//Bulletin of the Samara municipal Institute of management 2015 No 2 81-93 